\title{
Assessing the shipping in the Northern Sea Route: a qualitative approach
}

Po-Hsing Tseng

Department of Transportation and Logistics, Feng Chia University, Taichung, Taiwan, and

Nick Pilcher

The Business School, Edinburgh Napier University, Edinburgh, UK
Shipping in the

Northern Sea

Route

389

Received 1 June 2017

Revised 30 August 2017

12 October 2017

Accepted 14 November 2017

\begin{abstract}
Purpose - The Northern Sea Route (NSR) could become viable in the near future. If this happens, it will radically reduce sailing times and distances on routes from Asia to Northern Europe. However, although much has been written about the feasibility of the NSR, about the issues involved and about the possible opening of the route, the views of key stakeholders from companies who would potentially benefit from the route have been little explored. The purpose of this paper is to complement the existing literature on the feasibility of and issues related to the NSR by presenting and discussing the results from in-depth qualitative interviews with nine key stakeholders based in Shanghai and Taiwan who have extensive research, knowledge and practical experience of NSR.
\end{abstract}

Design/methodology/approach - Based on a grounded theory analysis, a total of nine key stakeholders knowledgeable about NSR and the majority with sailing experience of NSR are interviewed, including one government official, two professors, shipping experts in six liner and one bulk shipping companies.

Findings - The authors present interviewees' thoughts regarding the feasibility of NSR at the current time in terms of practicalities, ships, costs, information and wider issues.

Practical implications - These thoughts show that whilst the potential of NSR is huge in theory, in practice the overall perception of it in terms of current feasibility from a company perspective is one of challenges and unknown issues. Shipping companies can benefit from the authors findings when considering the feasibility of NSR as a shipping route. Ultimately, the picture emerges that without one country, probably Russia, taking the lead on the route, it will remain only a theoretical one.

Originality/value - In-depth interviews with grounded theory are used to investigate current and actual thoughts on NSR. This paper highlights correlations and additions to show a fuller picture of current knowledge and adds views from Shanghai and Taiwan.

Keywords Grounded theory, Interview, Shipping, Northern Sea Route

Paper type Research paper

\section{Introduction: potential and possibility of North Sea Route}

Maritime routes linking Asia and Europe and North America have become the principal axes of container transport (Verny and Grigentin, 2009, p. 109). Based on UNCTAD

(c) Pacific Star Group Education Foundation.

This research did not receive any specific grant from funding agencies in the public, commercial or not-for-profit sectors.

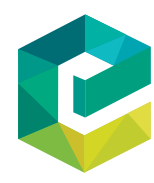

Maritime Business Review Vol. 2 No. 4,2017 pp. $389-409$

Emerald Publishing Limited $2397-3757$
shing Limited 
MABR

2,4

390
Figure 1.

Comparison of traditional and Northern Sea Route for Yokohama, Busan, Shanghai and Kaohsiung statistics, vessel port calls in Asia and Europe accounted for 80.2 per cent of global vessel port calls in 2015, and this has greatly increased recently (UNCTAD, 2016).

Much traffic now leaves from Northern China (Verny and Grigentin, 2009) with seven Chinese ports now in the world's top ten container terminals[1]. Of Northern Polar routes between North America, Europe and Asia, three principal ones are the transpolar route (TSR), the Northwest Passage (NWP) through the Canadian Arctic and the Northern Sea Route (NSR) along the Russian coast (Hong, 2012). TSR is the riskiest, running through the middle of the Arctic Ocean (Humpert and Raspotnik, 2012), whereas NWP and NSR are coastally based. NWP connects the Atlantic and Pacific Oceans along the northern coast of North America via the Canadian Arctic Archipelago. NSR connects the Atlantic Ocean to the Pacific Ocean along the Russian coast of Siberia, via mostly Russian Arctic waters. In this paper, we focus on NSR, given its relation to trade between Europe and far East Asian ports such as Yokohama and Busan but also including Shanghai and Kaohsiung (see Figure 1) and draw on data from in-depth interviews with stakeholders working in ports that would use NSR. Both Shanghai and Kaohsiung are ports with significant amounts of trade. According to the World Shipping Council (2017), Shanghai's volume of trade by million

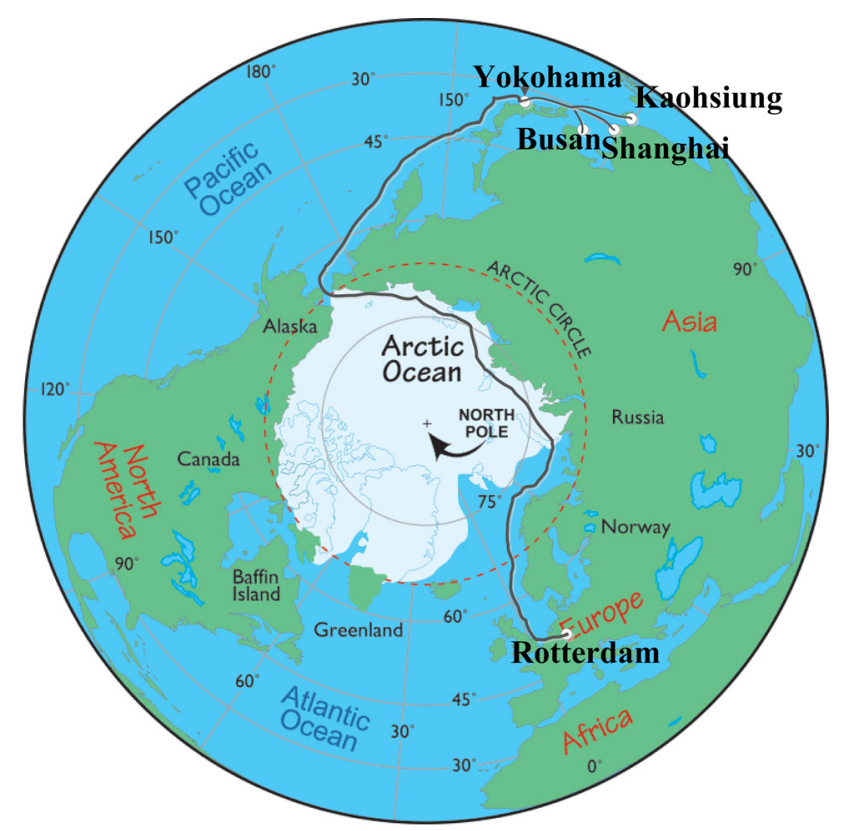

\begin{tabular}{|c|c|c|}
\hline Sailing Route & Traditional Route $(\mathrm{Nm})$ & NSR Route Estimates $(\mathrm{Nm})$ \\
\hline Yokohama $\rightarrow$ Rotterdam & 13,067 & 4,633 \\
\hline Busan $\rightarrow$ Rotterdam & 12,515 & 5,185 \\
\hline Shanghai $\rightarrow$ Rotterdam & 11,998 & 5,702 \\
\hline Kaohsiung $\rightarrow$ Rotterdam & 11,434 & 6,266 \\
\hline
\end{tabular}

Source: Map adapted from Google Maps and figure estimates based on Hong (2012) 
TEU was the highest in the world at 36.54 in 2015, and Kaohsiung's was ranked 13th at 10.26 million TEU. What is more, although the trade route between Asia to North America occupied the largest amount of cross-trade at 23,125,000 million TEU in 2013, the trade route between Asia and North Europe was ranked a clear second place with 13,706,000 million TEU (World Shipping Council, 2017). Our stakeholders were experts with much experience of sailing NSR and were based in Shanghai and Kaohsiung and ports in Taiwan (see section 3). They were thus fully aware of the possible significance of the opening up of NSR, and they had considerable experience of it in relation to the possibilities it would afford in terms of trade for Shipping in the Northern Sea Route the ports of Shanghai and Kaohsiung shown in Figure 1.

Regarding potential benefits, compared to the Suez Canal, NSR could cut 40 per cent (Liu and Kronbak, 2010; Lindstad et al., 2016), or approximately seven days, off journeys between Yokohama and Rotterdam. According to Hong (2012), this represents a reduction from 11,200 to 6,500 nautical miles, although according to other distance calculators, Yokohama to Rotterdam is a greater 13,067 nautical miles (Ports, 2017), which would in theory make the gains even greater for sailing NSR, by our estimations meaning this distance was only 4633Nm (6,500 minus the difference of 1867 between 11,200 (Hong, 2012) and 13,067 (Ports, 2017)). The Ports (2017) distance calculator calculates the distance from the major ports of Shanghai and Kaohsiung as slightly less but nevertheless similar as $11,998 \mathrm{Nm}$ and $11,434 \mathrm{Nm}$, respectively (ibid). Whatever the precise distance, it is clear that sailing from these ports through NSR would represent huge reductions in the amount of nautical miles required for sailing, and the route is rightly described as being one which "will connect East Asia (Japan, South Korea, Taiwan and China) with Northwestern Europe through the Arctic Ocean" (Bekkers et al., 2016, p.2). We estimate these differences in the table accompanying Figure 1 above. Such distance reductions would save fuel, reduce emissions (DNV, 2010; Furuichi and Otsuka, 2013) and save time (Schøyen and Bråthen, 2011), making it twice as energy efficient (Schøyen and Bråthen, 2011) and a significant business opportunity for many countries (e.g. South Korea (Bennett, 2014)). In 2017, a Russian tanker carried a cargo of liquefied natural gas (LNG) from Hammerfest in Norway to Boryeong in South Korea in 19 days. It is estimated that it saved about 30 per cent time than the conventional southern shipping route through the Suez Canal (Guardian, 2017)[2].

Furthermore, combining NSR with other routes could increase annual shipping capacity (Furuichi and Otsuka, 2013), which is a highly appealing prospect given that pressure on the Suez canal means it may soon reach capacity (Drewry, 2008; Verny and Grigentin, 2009, p.109). Also, in recent years, China, Japan and Korea have successfully navigated the NSR (Stokke, 2013), and literature has commented on its potential for China (Hong, 2012), Korea (Bennett, 2014) and also Japan (Usami et al., 2016).

Nevertheless, there are many issues with NSR: sea ice and higher hazard levels (Laulajainen, 2009; Liu and Kronbak, 2010; Hong, 2012); higher risk of a reduced service (Hong, 2012); greater navigational needs (Liu and Kronbak, 2010); higher unit costs per distance travelled, given the need for ice strengthening and ice breaker support (Liu and Kronbak, 2010; Hong, 2012); higher ship building costs (Liu and Kronbak, 2010); and possible environmental impacts of oil spillage and increased air pollution (Schøyen and Bråthen, 2011). Crew training, protection of the cargo, the maintenance of both hulls and ship equipment are also extra concerns (Lee and Kim, 2015). In addition, navigating around sea ice means exact arrival times cannot be given, (Schøyen and Bråthen, 2011), which could represent an issue for shipping. Although recent aggregate time performance figures show that the liner shipping industry does not require perfect on time schedules, with some performances below 80 per cent (Port Technology, 2015), there is nevertheless a desire for greater reliability. In addition, container cargoes often require faster delivery times than 
MABR

2,4

bulk cargo and such timing issues may be more important to them. Further, ship owners will be faced with managerial difficulties in route rescheduling and also losses from ships travelling far less (Laulajainen, 2009), and the draft of ships may be limited in NSR (Schøyen and Bråthen, 2011), thus reducing possible TEU equivalents.

Of fundamental importance to any company's decision to use NSR is the fact that actually ascertaining what is known about NSR is highly complex. Assessment and quantifications of supply chain transport risks (Schøyen and Bråthen, 2011) are difficult, as is ascertaining when ice-free sailing will be possible (Lajeunesse, 2012). Further research is often called for (Furuichi and Otsuka, 2013), and some highlight a number of issues to address before NSR becomes feasible: establishing a polar code; improving Search and Rescue (SAR) services; improving infrastructure; political and legal agreements over tolls and permissions (Hong, 2012; Lee and Kim, 2015).

One continent that would use NSR should it become navigable is Asia. Asian shipping companies represent a huge proportion of the trade that uses traditional routes and would potentially benefit greatly from an NSR route through the reduced shipping times and savings it would potentially offer on routes to Europe. Yet, little research to date has studied what they think and almost none has adopted qualitative approaches. Some research has used surveys (Beveridge et al., 2016) and found that at the moment such a route is not one that Asian companies would consider. In this paper, we complement such research by presenting and discussing findings from an in-depth qualitative study with key stakeholders involved in shipping in Asia from Shanghai and Taiwan. We present their views regarding the current potential of NSR and their thoughts on the feasibility of it. Qualitative approaches are often used by companies to test products at a user-interface level (Bosch-Sijtsema and Bosch, 2015) after they have been quantitatively explored, and those are often used in logistics as initial studies before more in-depth quantitative or semi-quantitative studies are used (American Institute of Chemical Engineers, 1995). Here, our purpose in using qualitative approaches is to provide a complementary in-depth perspective alongside existing survey research and in addition to test current thinking with a view to comparing it to the extant literature.

The remainder of our paper is structured as follows. We first review some of the key literature in the field. We then detail our methodology and approach to gathering key stakeholder perspectives regarding current thinking on NSR from nine experts on NSR, six of whom have sailing experience of NSR. Following this, we discuss these in light of the literature before drawing together the main points in the conclusion.

\section{Literature review}

This literature review is divided into: technical issues, ships, costs, information and other issues. We stress at the outset that although we deal with these areas discretely, we recognise that there is substantial overlap and interrelation. Consequently, in a final section, we summarise the main points from the literature to bring the points together clearly.

\subsection{Technical issues}

By technical issues we mean issues that can affect the practical sailing of NSR. One practical issue relates to infrastructure. Although some literature notes past Soviet development of ports along the Siberian coast, much notes the inadequacy of this infrastructure regarding practical facilities or SAR for ships encountering pressured ice (Mussells et al., 2017), growler ice or other problems (Verny and Grigentin, 2009). Such ice and problems may continue many years into the future (Renfrow, 2006; Lajeunesse, 2012) and forecasting for aspects such as growler ice and ice sheet movements are fundamental to making NSR 
feasible (Hong, 2012; Ho, 2010) as is recovering any oil spills (Hong, 2012). However, SAR and navigation technology is highly costly (Laulajainen, 2009).

Another technical issue is that the free passage season in NSR currently only runs from summer to autumn. To make NSR more commercially viable, timely and sufficient products for shipping in destinations (i.e. markets of Asia and Europe) and stop-by locations (i.e., local Russian markets) are critical. Thus, it is argued that a stable company financial status and high-level manager support are necessary to facilitate long-term investment in the potential of NSR (Lee and Kim, 2015). In the many models discussing NSR's feasibility, different Shipping in the Northern Sea Route sailing speeds for summer and winter and by different researchers are considered, and all these factors are inextricably linked to technical issues of cost, logistics and information (Lasserre, 2014). One practical issue that NSR would help avoid according to the literature is that of piracy. NSR avoids both areas where piracy exists and also avoids politically unstable Middle Eastern Waters (Hong, 2012). This is not of course to suggest that piracy could not occur there.

\subsection{Ships}

To date, the research is somewhat conflicting regarding the size of vessels that can travel through NSR, possibly because the coastal route of NSR involves travel through the Sannikov Strait (Pastusiak, 2016), which has a limited depth, whereas the transit route is in more open, deeper seas. Whatever the reason, it is clearly an issue that companies need to carefully consider. For example, although Hong (2012) notes there are no vessel restrictions on NSR, and some Korean based research has found that bulk and oil tankers are more viable than containers for navigation in the NSR (Lee and Kim, 2015), others note the draft of vessels cannot exceed 13 metres owing to the limited depth of the Sannikov straight (Verny and Grigentin, 2009; Liu and Kronbak, 2010) and that this will impact on profitability (Stephenson et al., 2013). Also, ships must be ice-class, even when being escorted by an ice-breaker (Lindstad et al., 2016). Remaining sea ice will also increase the power requirement of ships. There are clear cost implications here. Furuichi and Otsuka (2013) note that such ships cost an extra 10-30 per cent to build and loans may be needed to pay for such ships (Verny and Grigentin, 2009; Liu and Kronbak, 2010). Significant engineering is required, including hull thickening, greater structural support, rudder and propeller protection and heating for fuel tanks (Liu and Kronbak, 2010). Nevertheless, such technology does exist (Ho, 2010; Hong, 2012), and there is a desire to build such ships, for example on the part of South Korea (Hong, 2012; Bennett, 2014), and they are listed on Lloyd's register (Liu and Kronbak, 2010) making insurance matters more straightforward.

\subsection{Costs}

Put simply: "everything costs more for the shipping service in the Arctic" (Lasserre, 2014, p.155; compare also Tavasszy et al., 2011) and the range and complexity of costs involved in NSR is immense. Liu and Kronbak (2010) categorise these costs into capital costs (e.g. ships); voyage costs (e.g. toll fees); and operation costs, (e.g. insurance (both Protection and indemnity (P\&I) and Hull \& Machinery (H\&M)). According to Somanathan et al. (2009), annual cost estimation of each ship type for a potential route should include both operating cost and capital recovery (or at least cost). The total cost of the whole fleet in one year thus includes operating cost, capital cost and payments and voyage cost (Lee and Kim, 2015). Operating costs include crew wages, repairs and maintenance, insurance fees and administration. Capital cost and payments include interests, debt repayment and depreciation. Voyage cost includes fuel consumption, supply of fresh water, port charges and pilot and ice-breaker tariffs. Regarding fuel costs, savings may be immense, but these 
MABR

2,4 may be offset by the need for specialised types of fuel (Lasserre, 2014) and a low fuel price might make NSR less attractive (Pierre and Oliveier, 2015). Further, although some suggest slow steaming to reduce operational fuel costs (Tavasszy et al., 2011), this might not be possible given just in time requirements and navigation difficulties (Lasserre, 2014). Also, ice-class ships with reinforced hulls consume more fuel (Furuichi and Otsuka, 2013).

Insurance costs, although higher, are extremely hard to ascertain (Verny and Grigentin, 2009) and some insurers do not yet offer insurance (Lajeunesse, 2012). Further, there are costs for administration, tariffs, fees for guidance and meteorological information. Such costs are currently imposed by Russia, are approximately double those on the Suez route (Verny and Grigentin, 2009) and differ according to the specific NSR region (Liu and Kronbak, 2010), making cost calculations of this element highly complex. Another cost is the skilled crew required (Verny and Grigentin, 2009; Ho, 2010; Lajeunesse, 2012). A crew of 19 would cost US $\$ 100,000$ per month (Verny and Grigentin, 2009). Some suggest introducing an Arctic Certificate (Laulajainen, 2009) as much technical support, know-how, navigation equipment, escort and experience is needed to take ships through NSR (Verny and Grigentin, 2009).

Nevertheless, these additional costs must be considered alongside the savings of NSR. Crews may be more expensive, but sailing time is much reduced, so the crew would not be needed for as long (Hong, 2012). Insurance may be higher, but the reduced risk of piracy (Hong, 2012; Furuichi and Otsuka, 2013) or kidnapping (Schøyen and Bråthen, 2011) is a positive and hull insurance is the same for ice-class and standard class ships (Laulajainen, 2009). On balance, some argue NSR could "cut the cost of a single voyage by a large container ship billions of dollars a year" (Hong, 2012, p.50). Often, conclusions of profitability are based on "what if" scenarios: for example, if ice-breaker fees are reduced by 85 per cent and bunker fees kept low then NSR will be "as economically competitive" as the Suez canal if open for 3 months (Liu and Kronbak, 2010, p.443). A recent review of models aimed to calculate the profitability of Arctic routes shows 13 concluded yes; 6 were ambivalent; and 7 concluded no (Lasserre, 2014). Nevertheless, such "conclusions must be handled with great care" (Lasserre, 2014, p. 151). Also, others note that, given the greater impact of emissions when they are released in the arctic area, the benefits of any fuel savings are overridden by the environmental costs involved, thus eliminating any cost benefits in savings on emissions from an environmental perspective (Lindstad et al., 2016).

With regard to the impacts on shippers and consignees, NSR could bring more sailing frequencies (loop) between Asia and Europe and consequently result in cost reduction owing to shorter sailing distances and lead times. Shippers could adjust their maritime supply chain deployment in response to the demand of consignees according to the sailing season (e.g. June to September) of NSR. Further, based on the effect of shorter transportation distance, NSR could bring potential benefits in production, logistics, warehouse and distribution costs for shippers and consignees.

\subsection{Information about North Sea Route feasibility}

The models and simulations calculating the feasibility of NSR differ quite significantly. Often, certain factors are omitted, some models do not compute NSR fees, others imagine crew costs to be the same on Arctic and standard routes, insurance premiums fluctuate greatly (Lasserre, 2014). In addition, some researchers commendably critique their own models for only including simulations using single, rather than multiple vessels (Liu and Kronbak, 2010). The difficulties of defining credible parameters for any model are also noted (Lasserre, 2014) as is the scarcity of Siberian route data (Schøyen and Bråthen, 2011). 
Ascertaining NSR navigability is also highly complex. Historical data indicate rapid melting and significant increases in ice-free days (Schøyen and Bråthen, 2011) and, if some predictions are believed (Lovelock, 2009), NSR will very soon be navigable. Some claimed the Arctic Ocean would be navigable all year round by 2015 (Valsson, 2006). Others claim that a "blue" summertime Arctic Ocean could be from the middle of the century, although "current rates of warming indicate an earlier realization" (Ho, 2010, p. 713). Elsewhere however, a navigable season of only 90-100 days is not predicted until 2080, although thought to be a conservative prediction (Liu and Kronbak, 2010). Further, other literature

Shipping in the Northern Sea Route

395 cautiously observes that increased melting "may" lead to a longer navigation season (Hong, 2012, p. 50) or "could" rise to a certain level by 2080 (Pelletier and Lasserre, 2012, p. 559).

Fundamental to any NSR information is the specific method used to collect it. Some researchers use quantitative methods, others qualitative, others a mix. Some have used "informal discussions with actors in the maritime transport industry" (Verny and Grigentin, 2009, p. 108), others have used case study (Liu and Kronbak, 2010); interviews (12) and survey responses (18) (Lammers, 2009), email, telephone conversations and interviews (Schøyen and Bråthen, 2011); telephone interviews (Liu and Kronbak, 2010); qualitatively analysed surveys (Pelletier and Lasserre, 2012); model based analyses (Tavasszy et al., 2011) and Bayesian analyses (Afenyo et al., 2017). Many researchers highlight the drawbacks with their approaches, ranging from having too small a sample for quantitative analysis (Pelletier and Lasserre, 2012) to the difficulties of including everything in a model (Tavasszy et al., 2011). Regarding future research, many factors are suggested, such as including both quantitative and qualitative studies (Verny and Grigentin, 2009) and using quantitative modelling to help assess safety risk (Yang et al., 2013).

\subsection{Other issues}

Wider issues related to NSR involve possible political disputes over arctic waters (Ho, 2010; Hong, 2012; Wegge, 2015; Lee and Kim, 2015) and the need for clarification of legal issues (Hong, 2012) such as "an integrated governance and regulatory framework based on the United Nations Convention on the Law of the Sea" (Ho, 2010, p. 714). Further, whether the NSR should be considered as internal waters, territorial water, or international straits has debated for many years. Russia has claimed that most of NSR is under Russian jurisdiction (Flake, 2013), and many accept Russia will hold the rights to any NSR (Liu and Kronbak, 2010; Lajeunesse, 2012) and that rules and regulations for the Suez Canal are more transparent (Liu and Kronbak, 2010). Companies are thus subject to the political changes, rules and regulations of one particular country, unless an international law is passed. Therefore, uncertainties still remain in determining tariffs for the use of icebreakers and pilotage owing to the discretion of Russian authorities and negotiation with users.

Another issue is that the most benefit may be for companies wishing to extract natural resources, rather than for liner shipping, especially as arctic oil reserves are said to be comparable to Middle East reserves by some (Laulajainen, 2009), even if not by others (Pelletier and Lasserre, 2012). Indeed, Singapore and India have presented their interests in NSR, as it has plentiful natural resources (Ho, 2010). As a result, in the future, more shipping and natural resource exploration activities in NSR (including Arctic states and other countries which have interests in this area) might increase environmental risks (i.e. floating ice can strike tankers and barges and lead to oil spills, noise disturbance) to the marine ecosystem and residents along Siberian coast (Pierre and Oliveier, 2015). Satellite data monitoring shows the dangers to the environment of carrying wet bulk and how black carbon is associated with certain ship types (Mjelde et al., 2014). Sailing NSR could also have an impact on indigenous populations and the livelihood of indigenous species of whales and 
MABR 2,4 need to be carefully monitored (Reeves et al., 2014). It is suggested that management of Arctic shipping needs to be carefully planned in advance to protect endangered species of whales such as the North Atlantic Whale (Reeves et al., 2012). Furthermore, the effects of climate change are not all positive, as global warming involves "an increase in the frequency and intensity of adverse weather events" (Ho, 2010, p. 713).

Another wider issue is the possibility of new alternative routes and of changes in existing routes. Firstly, it is possible that a Trans-Siberian land route could become more attractive with Russian investment (Verny and Grigentin, 2009). Secondly, the Suez canal is "expected to see several improvements in years to come" (Verny and Grigentin, 2009, p. 116) and even if NSR becomes popular, it will require vessel traffic systems to prevent narrow straits becoming "choke points" (Ho, 2010, p. 714).

\subsection{Summary}

The literature above shows that much is known about the feasibility of NSR but also that it is uncertain. NSR offers the greatest potential between Asia and Northern Europe and, compared to the Suez Canal, distances are cut by almost 40 per cent, making great savings in fuel and time. Some companies are keen to invest in NSR technology and ice-class ships. Yet, NSR may be subject to reduced service, higher hazard levels, ships cost more to build, crews and pilotage cost more, environmental spillages could be more damaging and ship owners may not benefit from reduced voyage times. Regarding uncertainties, it is unknown when NSR will be ice-free, or what are the exact journey times around the ice are, or which routes are available to all ship types. There is also uncertainty regarding the supply chain transport risks, if NSR benefits container shipping and that many currently unknown elements need to be in place for NSR to succeed, such as a polar code, improved SAR, improved infrastructure, political and legal agreements over tolls. We now describe our methodology and approach to interviewing some key NSR stakeholders from Shanghai and Taiwan regarding their thoughts on NSR.

\section{Methodology}

From November 2014 to March 2015 in Shanghai and Taiwan (Taipei, Taichung, Taoyuan, Kaohsiung), we conducted in-depth interviews with nine key stakeholders knowledgeable about NSR, including one government official, two professors, shipping experts in six liner companies and one bulk shipping company. As shown above (introduction), sailing NSR from ports in these areas would hugely reduce the amount of nautical miles required to reach ports in Europe. Thus, although ports in Japan and Korea are situated nearer NSR, those we consider here would gain huge savings through NSR. Furthermore, given the huge amounts of shipping that travel from these ports, NSR thus represents a huge opportunity for shipping companies based here.

In terms of their knowledge and experience of NSR, the nine shipping experts have extensive research and practical experience in the polar shipping field and six have sailing experience of NSR. Such experience included participation and involvement in many international shipping and port policies, including polar shipping issues; research into ship safety management of ice-breaking ships in the arctic area and; extensive sailing experience in the arctic area and extensive knowledge of polar weather conditions, ice class ships, crew training for the arctic area and other NSR-related aspects. Job titles included general manager, director, senior manager, captain and vice president, and the companies they worked for were ranked in the top 15 global shipping companies in 2014. Thus, they were stakeholders who could give perspectives on NSR from government perspectives, academic perspectives and both bulk and liner shipping industry perspectives. Importantly, they all 
had significant recent knowledge and experience of NSR, and they were working in highly influential roles in Asian shipping. Thus, not only was their knowledge and experience key but also their influence and positions are also key in relation to any decisions made with regard to choosing to sail NSR at this point in time.

In terms of the backgrounds of the stakeholders we spoke to and how we identified our participants to ensure their background and experience was relevant to NSR, our aim with selecting a broad range of individuals rather than focus on a specific group was to gather a wide range of perspectives and knowledge. We felt this important, given that we wanted to

create information to benefit those considering NSR, and we felt that this information would be more comprehensive and beneficial if it considered a broader range of perspectives. Such an approach we felt would be complementary to others that have focused on particular groups (e.g. shipping companies (Lee and Kim, 2015).

With regard to the key interview questions proposed and some follow-up questions, these focused on stakeholders' knowledge about NSR and what they felt were the challenges and practical issues involved, as well as whether they felt NSR viable at the present time. These questions were deliberately relatively open and broad, for example:

Q1. What are your concerns if this route becomes a business route in the future?

Q2. Do you think NSR is a feasible alternative route to traditional shipping routes?

Q3. What are main challenges for the shipping industries if NSR become an alternative route between Asia and Europe?

Q4. Do you think NSR could bring cost reduction for shipping industries? If yes, why? If No, why?

Q5. Do you have any comments or thinking about this issue?

Such questions were deliberately open and broad so as not to bias the collection through questions overly specified by the researchers (Chenail, 2011) and to allow for more open dialogue (Bakhtin and Holquist, 1981).

We used interviews rather than questionnaires (Beveridge et al., 2016) or focus groups to access more in-depth views through dialogue (Bakhtin and Holquist, 1981) with individuals and also to avoid a situation whereby we were asking participants to choose from perspectives that we had selected, as would have been the case questionnaires (Galasiński and Kozłowska, 2010). The interviews were much freer and thus allowed participants to convey information we ourselves had not considered. In terms of the language used, the interviews were conducted in the participants' native language (Cortazzi et al., 2011), recorded, transcribed verbatim by the interviewer to start the analysis (Bird, 2005), then translated into English using a goal oriented or "skopos" approach (Vermeer, 2004) which focused on the target language meaning rather than literal translation from the source language. These interviews were then verified by one of the authors, a native English speaker. Ethical approval was granted from the appropriate bodies and anonymity assured (Christians, 2011). Interviewees were assured that the interviews had been ethically approved and in this way felt freer to disclose information, thereby enhancing the validity of the interviews.

Interview data were analyzed using both objectivist and constructivist grounded theory approaches (cf. Charmaz, 2011). In essence, a grounded theory approach consists of one where data are approached from the "ground" with a "theory". In other words, data are collected and then a theory is taken to the data to analyse it for the occurrence and frequency of particular themes and items (Glaser and Strauss, 1967). From this original construct, 
MABR

2,4 grounded theory has developed and two key strains of the theory are now considered to be "objectivist" and "constructivist" (Charmaz, 2011). An objectivist approach analyses the data using already decided and pre-determined themes from the literature review and a constructivist grounded theory approach looks at the data but does so with very few already decided and pre-determined themes, and this therefore allowed for additional themes to emerge. In our analysis of the data for this paper, we used a combination of predetermined themes (i.e. objectivist grounded theory) and continually searched for emergent themes (i.e. constructivist). We found such an approach gave us the foundation of the predetermined key areas (objectivist) but at the same time offered the flexibility to explore new and emergent themes (constructivist). Our aim was to gather a wide range of items of theoretical occurrence (Flyvbjerg, 2006) and for consideration by others in their own context. It was in this paper therefore not an aim to seek any difference in participants' answers in relation to their backgrounds, rather, the aim was to gather a body of data for comparison with current research and thinking. Further, rather than approach the data for the frequency of occurrence of items in a content analysis as would be done, for example, with survey questionnaire responses, the aim was instead to align the data with the sections we had reviewed in the literature, and thus the analysis was approached more thematically. In particular, our aim was not only to analyze where there was concurrence with the literature but also where participants referred to elements that we had not encountered in the literature. The latter we were particularly interested in as these elements were novel from a theoretical occurrence perspective (Flyvbjerg, 2006). This form of analysis of the data was more reliable and valid in the context of our own aim and approach (Pilcher and Cortazzi, 2016), as it helped build a more comprehensive list of items for consideration.

\section{Results and analysis}

Below we present and discuss our data with the twofold aim of showing where our stakeholders' views corresponded with the literature, and where they differed or added to the literature. We cite stakeholder comments in italics and double quotation marks and bracket stakeholder background afterwards. All quotes are from participants and, although we refer to the literature in brackets throughout for comparison, we do not present any quotes from the literature, only from participants. As with the literature review, the sections we categorise our results by are: technical issues; ships; costs; information about NSR feasibility and other issues.

Our approach and our data are qualitative. In line with commonly adopted approaches for presenting and analysing qualitative data we do this in the form of quotes that are compared and contrasted with the literature. However, we present a summary of these results first here below in Table I: "Summary of key points and their implications". We do this for three main reasons: to first give an overview of the key points noted by the stakeholders we spoke to; to secondly show how these points compare or expand on the literature, and thirdly to give a judgement of what the implications of thee points are for NSR in our judgement. It is our intention that this initial summary will help contextualise the following more in-depth section as well as provide an overview and summary of the results and implications.

\subsection{Technical issues}

Regarding the practical issues of NSR, Stakeholders' views correlated with much of the literature. Regarding navigation (Renfrow, 2006; Lajeunesse, 2012) stakeholders noted that "communication and navigation systems are quite important" (Liner shipping), that there is a need for an "electronic chart system" and "communication and navigation facilities" (Liner 


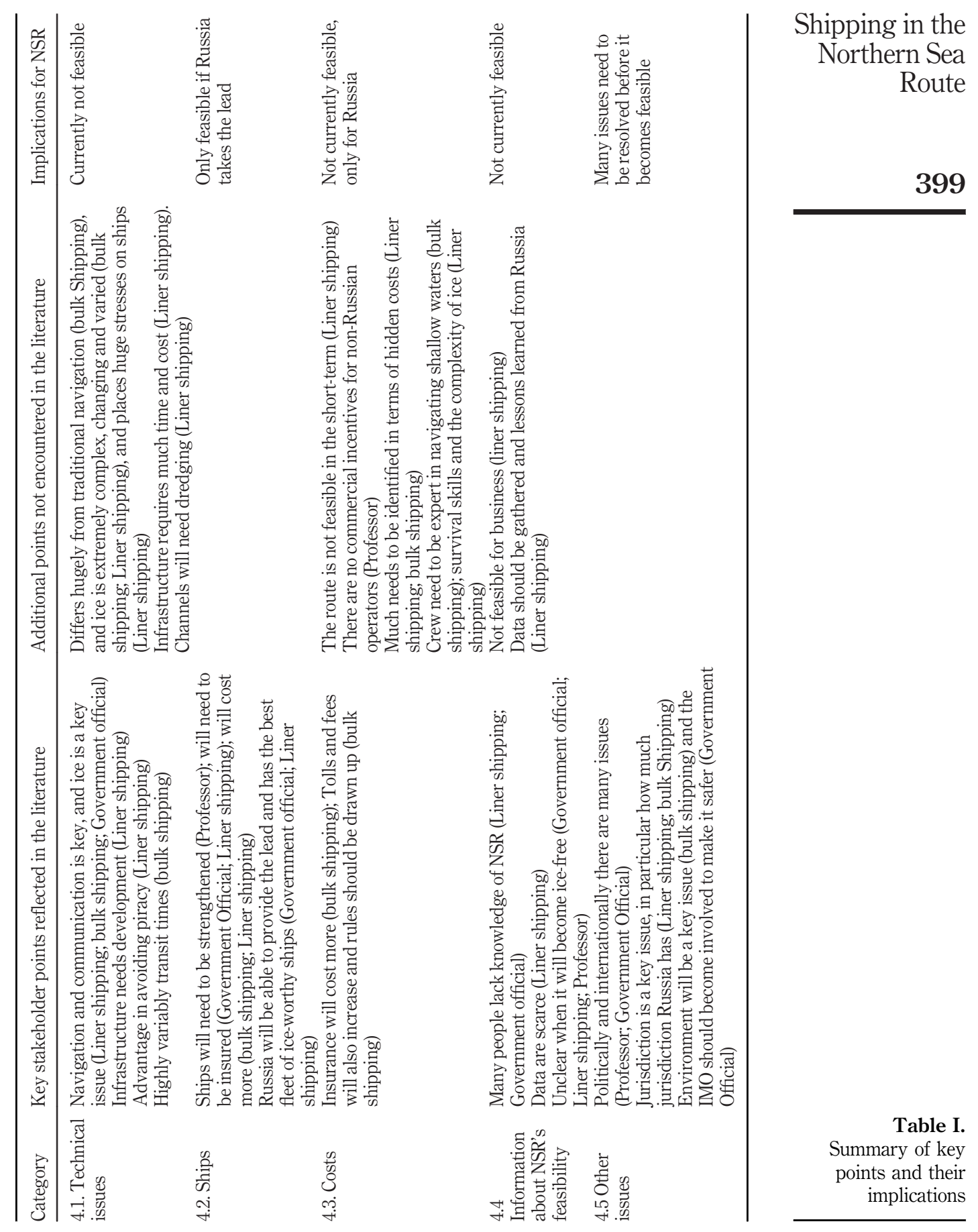


MABR

2,4

shipping) or "navigation and hydrographical support for arctic navigation, a navigation monitoring system" (Government Official). Such "advanced electronic navigational aids should be installed along the route" (bulk shipping). In addition to these similarities with the literature, stakeholders comments added much detail about specific navigation systems, noting that "navigation and ship control along the NSR are different from traditional methods, they need to locate ice fields and then choose coastal navigation routes" (bulk shipping). Consequently, development of navigation systems would take "time and much cost to develop a communication system that is well applied in NSR" (Liner shipping). Further, although "Automatic Identification System (AIS) could track ship position [... . it needs a base station to support the necessary data" (Liner shipping) and such data relies on artificial satellites (Liner shipping, Government official), but signals may be unstable in polar regions owing to poor weather, sea waves affecting antenna functioning, slow transmission speed, or confusion with other ships' signals. It was also felt sailing safety should be ensured by a "navigational hydrographic, hydro meteorological navigation service" (Professor). Sometimes system types were suggested such as "GLONASS (Global Navigation Satellite System)/GPS navigation satellite systems" or a "suitable gyro erectional navigation facility when sailing in high latitude areas" (Liner shipping).

Stakeholders' views also correlated with the literature (Hong, 2012) that there would be an advantage of "reducing risks when ships pass Somalia" (Liner shipping) and that ships, "can avoid pirate risk (e.g. Strait of Malacca and Suez Canal)" (Liner shipping). Also, the practical issue of not being able to fix exact sailing times (Lasserre, 2014) was also mentioned by stakeholders: "transit time via the NSR is highly variable and it depends on weather and ice conditions" (bulk shipping). Practical issues from ice affecting navigability (Hong, 2012) were also noted by stakeholders: "multi-year ice, especially in low concentrations, is a major hazard to shipping in this area" (Professor) and there is "dangerous drift (e.g. iceberg)" (Liner shipping).

However, stakeholders gave many additional details to those in the literature about the complexity and nature of the ice, that "it is difficult to anchor in ice areas, the helm can be broken owing to ice, there are incorrect magnetic fields and ship collisions" (Liner shipping). Further, the need to consider, "the thickness, the duration of the ice season, the extent of ice-free waters, temperature, wind, fog, darkness, the width of the channel, depth of water, permafrost, etc., these [...] factors will affect the accurate positioning of ships" (bulk shipping). Also, that ships' operational effectiveness is compromised by cold temperatures, as "when ice is present, it can impose additional loads on the hull, propulsion system and appendages" (Liner shipping).

Regarding infrastructure, the literature (Renfrow, 2006; Verny and Grigentin, 2009) highlights the need for more infrastructure and port facilities. Stakeholders concurred, noting that NSR "lacks sufficient infrastructure [.. . ] and lacks supply capabilities owing to the limited infrastructure around the port cities" (Liner shipping) but also noting that "it needs time and cost to construct adequate port facilities and infrastructure" (bulk shipping). Many factors, such as the need for SAR arose in both literature and stakeholder perspectives but stakeholders also noted additional factors such as the need for "navigation channel dredging" (Liner shipping).

Thus, regarding technical issues, our stakeholders were fully aware of all the issues we had seen in the literature and were better informed than we were. From this perspective, it is arguable that the likelihood of NSR becoming feasible looks further into the future than some of the literature would suggest. Such a pattern was repeated throughout all categories. 
Many ship-related aspects from the literature were also noted by stakeholders. For example, the need for ships to withstand ice involved many aspects of design and engineering (Liu and Kronbak, 2010), related to "ship hull [...] and machinery construction rules" (Professor) and the fact that such ships were uncommon. That ships needed certification to be on Lloyds register (Liu and Kronbak, 2010) and that ships would need an "official certificate to make sure they are safe for sailing" (Government Official) or "certification from the International Association of Classification Societies" (Liner shipping). Regarding the cost of developing such ships, although Furuichi and Otsuka (2013) noted such ships cost an extra $10-30$ per cent, the stakeholder view was that it would be higher: "about $20 \sim 30$ per cent higher" (Liner shipping), or that it was "on average more expensive" (bulk shipping).

As noted above, the literature is divided on the issue of whether certain routes would have draft limitations (contrast Hong, 2012 and Liu and Kronbak, 2010). Our stakeholders felt similarly, some that there was an issue with ship drafts, noting that, "draft restriction is another problem" (bulk shipping) and that large ships, "must suit the [...] draft limitations for navigation through several straits via the NSR" (Liner shipping). Yet, one stakeholder felt draft limitations were not an issue, and in fact quite the converse compared to traditional routes:

There is a draft limitation in the Panama and Suez canal. Ships with a large deadweight must go round by Cape of Good Hope in South Africa or the southern point of South America. (Liner shipping).

Also similarly to the literature, one stakeholder noted that given the distances involved, "the volume of transportation must be sufficient since the sailing distance between Asia to Europe is very long" (Governmental official).

As with their knowledge of the practical issues, many stakeholders talked specifically about Russia's fleet, noting Russia has "one of the best ice-breaking fleets in the world. Besides ice-breaking fleet, it includes [...].facilities for control and prevention of pollution of arctic waters" (Governmental official). Further, that "Russia has adopted nuclear-powered icebreakers in military projects" (Liner shipping) and that ice-breakers are able to "guide 1-4 ships to pass through the ice area" and that "two ice-breaking ships will be allocated to be the leading ship and the tail ship" (Liner shipping). Positively, one stakeholder noted that if demand for such ships increases, "it will also bring a business opportunity for the ship building industry" (Liner shipping). There was thus a clear feeling here that should NSR become operable, much of the SAR and guidance facilities could be provided by Russia.

\subsection{Costs}

Regarding the categorisation of costs, the literature has divided these into capital (ship related); voyage (e.g. tolls) and operation (e.g. insurance costs) (Liu and Kronbak, 2010). Occasionally, our stakeholders also categorised costs, but did so slightly differently, for example that

A ship's running cost can be separated into the following three categories: Operation cost (including manning costs, stores and lubricants, repairs and maintenance, insurance, administration). Capital cost and payments (including interests, debt repayment, depreciation). Voyage cost (including fuel oil, port cost, canal due (if any), ice-breaking fee)" (Liner shipping).

Regarding the costs of individual elements, crew costs for NSR are higher according to the literature, for example that a crew of 19 would cost US $\$ 100,000$ per month (Verny and Grigentin, 2009). Our stakeholders agreed, and whilst they only averred to crew cost being 
MABR

2,4

higher, they gave many additional details about what NSR crew would need to know, such as that "shallow waters in the navigation routes passing along the northern coasts of Russia require increased attention and experience from ship crews" (bulk shipping). More specifically, crew would need "skill for surviving, using survival facilities in the low temperature environment, first aid and treatment, safe evacuation, ice/snow forecasting skill" (Liner shipping). Further, one stakeholder added that:

Captains must understand the composition of ice and its characteristics, operating in ice areas, hull stress due to ice and low temperatures, safe sailing operations, ice-breaking operations, and ship stability control (Liner shipping).

In terms of insurance and administration fees, echoing the literature, (Verny and Grigentin, 2009), stakeholders highlighted the importance of insurance, one commenting that "the insurance cost (including cargo and ship) will increase if the owners would like to try this route" (bulk shipping). Also, stakeholders highlighted the need for more rules and regulations regarding tolls and fee charging (Hong, 2012), one stakeholder noting that:

Rules and regulations should be established and developed by the International Maritime Organisation (IMO). Many shipping companies would hope that fee charging for travelling the

NSR should be realistic, acceptable and predictable (bulk shipping).

As far as NSR's feasibility was concerned the literature often focused on events and possibilities, such as an 85 per cent reduction in ice-breaker fees improving feasibility (Liu and Kronbak, 2010), or that 13 of 26 studies concluded NSR was profitable (Lasserre, 2014). For stakeholders, it was often more in the long-term NSR would become feasible, for example that "this route does not have commerce feasibility in the short term" (Liner shipping) or that NSR "might bring some benefits to shipping companies at first glance [...] .however [...] .it cannot save much money at this time" (Liner shipping). Also, even where companies had actually sailed NSR and saved "9 days sailing compared to the traditional route [...]. but some analysts indicated that it needs time to make it a popular sailing route since it lacks port infrastructure" (Liner shipping).

As with other aspects above, our stakeholders mentioned additional elements to the literature. One was linking costs to the Russian context, for example that, "I do not see commercial incentives for the use of NSR for non-Russian operators" (Professor). Other cost related elements were, in line with the element of known unknowns, what were termed "hidden" costs, that NSR would "increase hidden costs and could affect their service quality" (Liner shipping) or simply that "the hidden costs require further calculation" (bulk shipping). Examples of these were often ones noted in the literature but also others such as "cargo damage due to low temperature and temperature variation" (bulk shipping) were noted.

\subsection{Information about North Sea Route's feasibility}

Resonant with the literature commenting on the complexity of drawing conclusions about NSR (Lasserre, 2014), our stakeholders commented that many people lacked knowledge about NSR. For example, that "many shipping operators do not understand this area well since there exists many uncertain factors that need to be considered" (Liner shipping) and that "Many shipping operators have a poor understanding of the Arctic environment" (Government official). Also, as in the literature (cf. Schøyen and Bråthen, 2011), the scarcity of data was noted, one stakeholder saying "there is no correct sailing data in the polar area. Maybe only Russia has this kind of sailing data” (Liner shipping). 
Also resonant of the literature, our stakeholders had divergent views on when NSR would become ice-free. One stakeholder commented that "one expert predicted ships might sail the NSR over four seasons by the year 2030" (Liner shipping). Another commented on the importance of minerals and resources: "NSR [... . could be another alternative place to purchase energy for China. Therefore, it could drive the trade development between China and the Arctic countries" (Liner shipping). The sense of inevitability of NSR opening up was alluded to, with the fact that "In summer 2009, the first international ship has passed through the NSR" (Liner shipping) or that "in the future, global shipping network will be reshaped by the NSR and form a new picture of the shipping network" (Professor). One stakeholder believed a pioneering company would take the lead for NSR, then others would follow:

It should be a pioneer such as Maersk line since it is the top shipping company in the world. Then, other shipping companies (e.g. Mediterranean Shipping Company (MSC), CMA CGM Group) might follow it in order to maintain the market position (Governmental official).

In contrast though, one of our stakeholders from Maersk, commented that, "this route is mainly used for military affairs and strategies [...] For business consideration, there is no shipping company would like to choose this route" (Liner shipping).

In relation to methods that could be used to gather data, our stakeholders occasionally suggested methods that were additional or complementary to those previously used by researchers. One additional method was to use scientific methods to gather and calculate data form the sea itself:

To understand and predict the extent of the arctic sea ice and multiyear sea ice changes, we should adopt scientific instruments and methods to simulate sea ice variables on seasonal, decadal and century time scales (Professor).

A complementary suggestion was to use interviews (Lammers, 2009) but to consult directly with Russian stakeholders and also to cooperate to learn from others:

I suggest to learn from the Russian experience and study how to build a firm and solid ship [...] in the future, shipping experts and polar experts should cooperate and exchange learning experiences (Liner shipping).

\subsection{Other issues}

The wider issues of political jurisdiction and the need for international codes (cf. Liu and Kronbak, 2010; Hong, 2012) were noted by our stakeholders. It was noted that "political sensitivity surrounds this area" (Professor) and that "Canada and Russia have both claimed the Arctic waterways as internal waters that pass through their Arctic region" (Government official). There was a tension where on one hand participants felt NSR waters should be international but on the other understood that Russia and Canada would want jurisdiction. For example that, "Russia views it as a domestic traffic route but other countries view it as an international traffic route" and this means that:

Russia requires other countries' ships to obtain sailing permission from Russia in advance and pay fees for ice-breaking and navigation services. Other countries might not agree [...] and will be afraid if it increases such a fee in the future. Such a fee should be formulated by international organizations such as IMO (Liner shipping).

Similarly, that "Russia presents some rules and regulations for international shipping in this area, yet many countries will argue against the Russian regulation policies" and that "for fair usage principle in this route, it should be treated as international waters" (bulk 
MABR

2,4

shipping). Nevertheless, one stakeholder understood why Russia would want jurisdiction, but felt the waters should be international:

It could be easily understood that Russia [. . .] would like to keep involvement in the NSR [...] since ships will bring pollution problems. However, the claims [ . . . w would increase the complexity of NSR for shipping activities. For example, Russia has presented "Regulations for Navigation on the Seaways of the Northern Sea Route" and that affects the intention of sailing along NSR for the world shipping industry as a whole (Liner shipping).

Indeed, the wider issue of environmental damage was noted by many stakeholders. One noted that as shipping operators are unfamiliar with NSR:

The risk of ship accidents will be higher, thereby increasing the risk of accidental release of oil spill. This will bring serious impacts on the environment and regional development, especially in high production periods (bulk shipping).

Regarding possible actions to mitigate against such dangers, one stakeholder suggested taxes to deal with the issues: "carbon tax or fuel tax might be levied in this area in the future" (Professor) and another suggested a forum for environmental and other issues:

We hope the shipping operators or IMO could create a user forum where shipping stakeholders could give feedback and suggestions to make it safer and environmentally considerate and bring sustainable economic and financial benefits (Government official).

\section{Discussion}

Taking into consideration what our stakeholders said, the feasibility of NSR for companies in China and Taiwan appears to be a more long term prospect than much of the literature would suggest. Positively, the literature notes that trade is set to increase, ports in China set to grow, and NSR has significant potential to save huge amounts of time and money compared to traditional routes and that a number of companies are keen to invest in NSR technology and ice-class ships. However, on NSR, service may be reduced, higher hazard levels exist, ships will be more expensive, crew training will cost more, environmental spillages could be more damaging, ship owners may not benefit as much and that more research is needed. From the perceptions of our stakeholders, these issues were all key ones that they were fully aware of, but our stakeholders also were aware of a number of further issues. Our stakeholders commented on the unique difference in navigational approaches in polar regions, on ship horsepower, on the effect of temperature on cargo and the high cost of cargo. Furthermore, stakeholders were fully aware of the many different types of ice, ice floes, ice thickness and ice layers. Furthermore, the fact that ships cannot anchor in ice and that there may be magnetic influence, collision, permafrost and helm breakage, additional loads on hulls, propulsion systems and appendages. Nevertheless, the perception as well that Russia has both the equipment and the expertise to help make NSR more feasible. Clearly then, there was a perception that NSR was very much of one whereby Russia would take the lead and that without this, the feasibility of NSR would be much reduced. In addition, from our stakeholders' perspectives, the possibility of a frequently navigated and used NSR appears more distant than according to much of the literature.

Regarding uncertainties, the literature notes it is uncertain when NSR will be ice-free, how long a journey may take, or which routes are available to all ship types. Another uncertainty is that of supply chain transport risks, whether NSR is of benefit for container shipping, and that a number of elements need to be in place for NSR to succeed such as a polar code, improved SAR, improved infrastructure and political and legal 
agreements over tolls. Again, our stakeholders were fully aware of all these uncertainties, and also they were fully aware of a number of additional uncertainties. Firstly, it is uncertain what navigation system will be most suitable. Secondly, it is uncertain how much time will be needed to develop the infrastructure. Thirdly, the number of hidden costs is uncertain, and we do not know a lot of information because we would need to collect it directly from the arctic sea or from Russian experts. Fourthly, we do not know how much fuel will increase by in price and that this could affect NSR, and finally, we do not know when or even if international treaties will be introduced or

Shipping in the Northern Sea Route whether jurisdiction will remain with Russia. Thus, again, from our stakeholders' perspectives, the feasibility of a frequently used and navigated NSR appears more distant in the future than it does in much of the literature. Is this a concern for the shipping industry? Should it be? At the moment, much of the literature appears imbued with an inevitability regarding NSR: it will happen, it is just a case of when. Yet, as the literature shows, this "just a case of when" is extremely uncertain. Furthermore, the views of the stakeholders we interviewed here would suggest that, unless someone or something takes a lead on NSR, its feasibility is in the distant rather than the more immediate future for these companies in China and Taiwan, two key areas that could benefit from any NSR were it to become feasible. This is our stakeholders seemed to intimate that Russia would be one country that could take a lead given its expertise and geographical oversight of the majority of NSR. But should Russia take a lead? Perhaps it should do so in tandem with the IMO? Arguably, we would suggest that future research could conduct quantitative analyses of cost-based focuses to ascertain the benefits of forcing the issue of NSR. If such analyses show that, all things considered, NSR would be beneficial to the shipping industry, then perhaps the IMO should indeed take a lead on NSR, perhaps in tandem with a country such as Russia.

\section{Conclusion}

Owing to the sea ice in polar regions gradually retreating, shipping in NSR attracts interest from the shipping related industries in the world. The potential of NSR is a tantalising one that could dramatically reduce shipping times and costs from Asia to Europe, and, according to some literature, this is something that could happen fairly soon, if not imminently. The literature has noted a number of practical issues nonetheless and also a number of considerations with regard to ships, costs, information about NSR and also wider issues. Practical issues relate to navigability, SAR, weather conditions and infrastructure, ships must be specially engineered for the conditions and costs of crew training and insurance are key. Regarding information about NSR and wider issues, the literature notes the complexities of ascertaining certain information regarding NSR, wider issues of who should govern the route and issues related to the environment and rights of the indigenous populations. Furthermore, survey research with Asian companies suggests that at the current time the route is not considered feasible. We complemented this literature by conducting in-depth interviews with nine key stakeholders with extensive research, knowledge and practical experience in the polar shipping field from China and Taiwan. This is despite there being more advocacy for Korea (Bennett, 2014) and Japan (Usami et al., 2016) to adopt the route and for more optimistic predictions about its use by China (Hong, 2012). Their perceptions reveal current thinking regarding the feasibility of NSR, and, given their positions and influence, represent a view of significant power in the context of any decisions made regarding whether NSR is used. All none stakeholders were aware of all the issues we had encountered in the literature and far more. For example, their knowledge of the 
MABR

2,4

practicalities were often far more refined, for example regarding different types of navigation systems. Further, their estimates were often higher than those of the literature, for example, estimating ship costs higher than the literature. They also felt that without one country taking the lead in developing NSR, its feasibility was far more theoretical than practical.

In terms of shipping therefore, the perceptions and current thinking of the stakeholders we interviewed suggests that the feasibility of NSR is a more distant one than much of the literature suggests. The literature, we noted, almost seems imbued with an inevitability with regard to the feasibility and opening of NSR, but such an inevitability is not borne out by those we spoke to, many of whom work directly in the shipping industry itself. Should the issue be forced? Should someone take a lead on NSR? Our stakeholders tended to intimate that if anyone did it would be Russia, given their knowledge, expertise in shipping and their geographical proximity with much of NSR. We suggested also that the IMO may want to become involved in something that investigated and suggested that to determine whether the issue of the feasibility of NSR was worth forcing, that analyses focusing on cost-benefits would be useful. By undertaking such analyses to an extent that could incorporate all elements involved would reveal whether the issue was indeed worth forcing, or whether the shipping industry should instead simply wait for the theory of a navigable NSR to become a practical reality, whenever that may be.

\section{Notes}

1. http://worldshipping.org/about-the-industry/global-trade/top-50-world-container-ports

2. https:/theguardian.com/environment/2017/aug/24/russian-tanker-sails-arctic-without-icebreakerfirst-time

\section{References}

Afenyo, M., Khan, F., Veitch, B. and Yang, M. (2017), "Arctic shipping accident scenario analysis using Bayesian Network approach”, Ocean Engineering, Vol. 133, pp. 224-230.

American Institute of Chemical Engineers (1995), Guidelines for Chemical Transportation Safety, Security, and Risk Management, Center for Chemical Process Society, New York.

Bakhtin, M.M. and Holquist, M. (1981), The Dialogic Imagination: Four Essays, University of Texas Press, Austin.

Bekkers, E., Francois, J.F. and Rojas-Romagosa, H. (2016), "Melting ice caps and the economic impact of opening the Northern sea route", The Economic Journal, Vol. 1, doi: 10.1111/ecoj.12460.

Bennett, M.M. (2014), "The maritime tiger: exploring South Korea's interests and role in the arctic", Strategic Analysis, Vol. 38 No. 6, pp. 886-903.

Beveridge, L., Fournier, M., Lasserre, F., Huang, L. and Têtu, P.L. (2016), "Interest of Asian shipping companies in navigating the arctic", Polar Science, Vol. 10 No. 3, pp. 404-414.

Bird, C.M. (2005), "How I stopped dreading and learned to love transcription", Qualitative Inquiry, Vol. 11 No. 2, pp. 226-248.

Bosch-Sijtsema, P. and Bosch, J. (2015), "User involvement throughout the innovation process in hightech industries", Journal of Product Innovation Management, Vol. 32 No. 5, pp. 793-807.

Charmaz, K. (2011), "Grounded theory methods in social justice research", in Denzin, N.K. and Lincoln, Y.S. (Eds), The Sage Handbook of Qualitative Research, Sage, Thousand Oaks, CA, pp. 359-380. 
Chenail, R.J. (2011), "Interviewing the investigator: Strategies for addressing instrumentation and researcher bias concerns in qualitative research", The Qualitative Report, Vol. 16 No. 1, p. 255.

Christians, C.G. (2011), "Ethics and politics in qualitative research", in Denzin, N.K. and Lincoln, Y.S. (Eds), The Sage Handbook of Qualitative Research, Sage, Thousand Oaks, CA, pp. 61-80.

Cortazzi, M., Pilcher, N. and Jin, L. (2011), "Language choices and 'blind shadows': investigating interviews with Chinese participants", Qualitative Research, Vol. 11 No. 6, pp. 505-535.

DNV (2010), "Shipping across the Arctic Ocean: a feasible option in 2030-2050 as a result of global warming?", Research and Innovation, Position Paper 04.

Drewry (2008), Container Forecast, Drewry Shipping Consultants, London.

Flake, L.E. (2013), "Navigating an ice-free arctic”, RUSI Journal, Vol. 158 No. 3, pp. 44-52.

Flyvbjerg, B. (2006), "Five misunderstandings about case-study research", Qualitative Inquiry, Vol. 12 No. 2, pp. 219-245.

Furuichi, M. and Otsuka, N. (2013), "Cost analysis of the Northern Sea Route (NSR) and the conventional route shipping”, Proceedings of IAME 2013 Conference, Marseille, 3-5 July, pp. 1-22.

Galasiński, D. and Kozłowska, O. (2010), "Questionnaires and lived experience: strategies of coping with the quantitative frame", Qualitative Inquiry, Vol. 16 No. 4, pp. 271-284.

Glaser, B.G. and Strauss, A.L. (1967), The Discovery of Grounded Theory: Strategies for Qualitative Research, Aldine, New York.

Guardian (2017), "Russian tanker sails through Arctic without icebreaker for first time", available at: www.theguardian.com/environment/2017/aug/24/russian-tanker-sails-arctic-without-icebreakerfirst-time (accessed 10 October 2017).

Ho, J. (2010), "The implications of Arctic sea ice decline on shipping", Marine Policy, Vol. 34 No. 3, pp. 713-715.

Hong, N. (2012), "The melting Arctic and its impact on China's maritime transport", Research in Transportation Economics, Vol. 35 No. 1, pp. 50-57.

Humpert, M. and Raspotnik, A. (2012), "The future of Arctic shipping along the transpolar sea route", Arctic Yearbook 2012, Northern Research Forum and the University of the Arctic Thematic Network, pp. 281-307, available at: www.arcticyearbook.com

Lajeunesse, A. (2012), "New Mediterranean: Arctic shipping prospects for the 21st century", Journal Maritime Law and Commerce, Vol. 43, p. 521.

Lammers, L.P. (2009), "The possibilities of container transit shipping via the Northern Sea Route-Using backcasting to gain insight in the paths that lead to a feasible Arctic shipping service", Master Thesis (Working Paper), TIL 5060, Delft University of Technology, Transport Infrastructure and Logistics (TIL), Delft.

Lasserre, F. (2014), "Case studies of shipping along arctic routes. Analysis and profitability perspectives for the container sector", Transportation Research Part A: Policy and Practice, Vol. 66, pp. 144-161.

Laulajainen, R. (2009), "The Arctic sea route", International Journal of Shipping and Transport Logistics, Vol. 1 No. 1, pp. 55-73.

Lee, T. and Kim, H.J. (2015), "Barriers of voyaging on the Northern sea route: a perspective from shipping companies", Marine Policy, Vol. 62, pp. 264-270.

Lindstad, H., Bright, R.M. and Stromman, A.H. (2016), "Economic savings linked to future Arctic shipping trade are at odds with climate change mitigation", Transport Policy, Vol. 45, pp. 24-30.

Liu, M. and Kronbak, J. (2010), "The potential economic viability of using the Northern sea route (NSR) as an alternative route between Asia and Europe", Journal of Transport Geography, Vol. 18 No. 3, pp. 434-444.

Lovelock, J. (2009), The Vanishing Face of Gaia: A Final Warning, Allen Lane, London. 
MABR

2,4

Mjelde, A., Martinsen, K., Eide, M. and Endresen, Ø. (2014), "Environmental accounting for Arctic shipping-a framework building on ship tracking data from satellites", Marine Pollution Bulletin, Vol. 87 No. 1, pp. 22-28.

Mussells, O., Dawson, J. and Howell, S. (2017), "Navigating pressured ice: risks and hazards for winter resource-based shipping in the Canadian Arctic", Ocean \& Coastal Management, Vol. 137, pp. 57-67.

Pastusiak, T. (2016), Northern Sea Route as a Shipping Lane, Springer, New York, NY.

Pelletier, S. and Lasserre, F. (2012), “Arctic shipping: future polar express Seaways: shipowners' opinion”, Journal of Maritime Law and Commerce, Vol. 43, pp. 553-564.

Pierre, C. and Oliveier, F. (2015), "Relevance of the Northern sea route (NSR) for bulk shipping", Transportation Research Part A: Policy and Practice, Vol. 78, pp. 337-346.

Pilcher, N., (2016), "Dialogues: QUANT researchers on QUAL methods", The Qualitative Report, Vol. 21 No. 3, pp. 450-473.

Port Technology (2015), "Container Shipping Reliability Nosedives”, available at: www.porttechnology. org/news/container_shipping_reliability_nosedives (accessed 11 August 2017).

Ports (2017), "Data on shipping distance calculations between ports of Rotterdam and Yokohama", Shanghai, and Kaohsiung, available at: http://ports.com/Last (accessed 11 August 2017).

Reeves, R., Rosa, C., George, J.C., Sheffield, G. and Moore, M. (2012), "Implications of Arctic industrial growth and strategies to mitigate future vessel and fishing gear impacts on bowhead whales", Marine Policy, Vol. 36 No. 2, pp. 454-462.

Reeves, R.R., Ewins, P.J., Agbayani, S., Heide-Jørgensen, M.P., Kovacs, K.M., Lydersen, C. and Blijleven, R. (2014), "Distribution of endemic cetaceans in relation to hydrocarbon development and commercial shipping in a warming Arctic", Marine Policy, Vol. 44, pp. 375-389.

Renfrow, S. (2006), Arctic Sea Ice on the Wane: Now What? Publications of National Snow and Ice Data Center, NASA, Colorado.

Schøyen, H. and Bråthen, S. (2011), "The Northern sea route versus the Suez Canal: cases from bulk shipping", Journal of Transport Geography, Vol. 19 No. 4, pp. 977-983.

Somanathan, S., Flynn, P. and Szymanski, J. (2009), "The Northwest Passage: a simulation", Transportation Research Part A: Policy and Practice, Vol. 43 No. 2, pp. 127-135.

Stephenson, R.S.R., Brigham, L.W. and Smith, L.C. (2013), "Marine accessibility along Russia's Northern sea route", Polar Geography, Vol. 37 No. 2, pp. 111-133.

Stokke, O.S. (2013), "The promise of involvement: Asia in the Arctic", Strategy Analysis, Vol. 38, pp. 784-802.

Tavasszy, L., Minderhoud, M., Perrin, J.F. and Notteboom, T. (2011), "A strategic network choice model for global container flows: specification, estimation and application", Journal of Transport Geography, Vol. 19 No. 6, pp. 1163-1172.

UNCTAD (2016), "Review of maritime transport 2016", United Nations Conference on Trade and Development.

Usami, T., Kato, H. and Shibasaki, R. (2016), "Impacts of using the Northern Sea Route on the macroeconomy and on liquefied natural gas import diversification in Japan", Transportation Research Board 95th Annual Meeting, No. 16-4845.

Valsson, T. (2006), How the World Will Change-with Global Warming, University of Iceland Press, Reykjavik.

Vermeer, H.J. (2004), Skopos and commission in translational action. in Venuti, L. (Ed.), The Translation Studies Reader, 2nd ed., Routledge, London, pp. 221-232.

Verny, J. and Grigentin, C. (2009), "Container shipping on the northern sea route", International Journal of Production Economics, Vol. 122 No. 1, pp. 107-117. 
Wegge, N. (2015), "The emerging politics of the Arctic Ocean: future management of the living marine resource”, Marine Policy, Vol. 51, pp. 331-338.

World Shipping Council (2017), "About the industry", available at: www.worldshipping.org/about-theindustry/global-trade/top-50-world-container-ports (accessed 10 October 2017).

Shipping in the Northern Sea

Route

Yang, Z.L., Wang, J. and Li, K.X. (2013), "Maritime safety analysis in retrospect", Maritime Policy \& Management, Vol. 40 No. 3, pp. 261-277.

\section{Further reading}

Fuglestvedt, J.S., Dalsøren, S.B., Samset, B.H., Berntsen, T., Myhre, G., Hodnebrog, O., Eide, M.S. and Bergh, T.F. (2014), "Climate penalty for shifting shipping to the arctic", Environmental Science \& Technology, Vol. 48 No. 22, pp. 13273-13279.

Leinbach, T. and Capineri, C. (2007), "Globalized Freight Transport: Intermodality, e-Commerce, Logistics and Sustainability", Transport Economic, Management and Policy Series, Edward Elgar, Cheltenham.

\section{Corresponding author}

Po-Hsing Tseng can be contacted at: Phtseng@fcu.edu.tw

For instructions on how to order reprints of this article, please visit our website: www.emeraldgrouppublishing.com/licensing/reprints.htm Or contact us for further details: permissions@emeraldinsight.com 